\title{
Selecting patients with hepatocellular carcinoma for liver transplantation: incorporating tumor biology criteria
}

This article was published in the following Dove Press journal: Journal of Hepatocellular Carcinoma

\author{
Víctor Amado \\ Manuel Rodríguez- \\ Perálvarez \\ Gustavo Ferrín \\ Manuel De la Mata \\ Department of Hepatology and Liver \\ Transplantation, Reina Sofía University \\ Hospital, IMIBIC, CIBERehd, Córdoba, \\ Spain
}

Correspondence: Manuel

Rodríguez-Perálvarez

Department of Hepatology and Liver

Transplantation, Reina Sofía University

Hospital, IMIBIC, CIBERehd, Avenida

Menéndez Pidal s/n, Córdoba I4004,

Spain

Tel +34957010286

Fax +34 957736014

Email ropeml@hotmail.com

\begin{abstract}
Liver transplantation (LT) is the optimal therapeutic option for patients with liver cirrhosis and hepatocellular carcinoma (HCC). Due to universal donor shortage, only the patients with limited tumor burden (under the so-called Milan criteria) are considered as potential candidates for LT in most institutions. It is expected that in the near future, more liver grafts will be available for patients with HCC due to the implementation of new direct antivirals against hepatitis $\mathrm{C}$, leaving a prone scenario to consider expanding Milan criteria. A moderate expansion of Milan criteria could be implemented without increasing the risk of tumor recurrence if patients with favorable biological behavior are carefully selected. Incorporating information regarding tumor biology in the decision-making algorithm would result in a more rational use of LT in patients with HCC. In the present review, surrogate markers of tumor biology are critically evaluated as potential tools to be combined with existing radiological criteria. In addition, the current state of liquid biopsy is discussed, as this cutting-edge technology may reshape the management of HCC in the upcoming years.
\end{abstract}

Keywords: cell-free DNA, locoregional ablation, alpha-fetoprotein, circulating tumor cells, liquid biopsy, biomarkers

\section{Introduction}

Liver transplantation (LT) is the only therapeutic option that is able to cure both hepatocellular carcinoma (HCC) and the underlying liver cirrhosis ${ }^{1}$ with 5 -year survival rates above $70 \%$ in most series, which are superior to any other treatment modality. ${ }^{2}$ However, tumor recurrence may affect up to $15 \%$ of patients, and should this complication occur, patients have limited therapeutic options and prognosis may be poor. ${ }^{1}$ In a setting characterized by donor paucity, it is central to optimize the access to LT. Only the patients with a reduced risk of posttransplant tumor recurrence are granted as potential candidates for LT. The current eligibility criteria for LT are mainly based on tumor burden assessed by dynamic imaging techniques. Most transplant institutions have implemented the so-called Milan criteria: ${ }^{3}$ a single nodule with a total diameter $\leq 5 \mathrm{~cm}$, or up to three nodules with a maximum diameter of $\leq 3 \mathrm{~cm}$ each, in the absence of macrovascular invasion or extrahepatic spreading.

Growing evidence supports a moderate expansion of Milan criteria. The upcoming of the new direct antiviral agents against hepatitis $\mathrm{C}$ has dramatically decreased the number of patients accessing the waiting lists for LT due to decompensated cirrhosis, ${ }^{2,4}$ thus leaving more donors available to consider expanding Milan criteria or at least to acknowledge downstaging as a routine approach. Previously proposed strategies 
consisted in increasing the number and/or diameter of HCC nodules accepted, being the most popular up-to-seven criteria, ${ }^{3}$ the Clínica Universitaria de Navarra (CUN) criteria ${ }^{5}$ and the University of Southern California-San Francisco (UCSF) criteria. ${ }^{6}$ However, expanding Milan criteria is accompanied by a parallel increase of tumor recurrence rates, leading to the Metroticket principle: the further the ride (in terms of pretransplant tumor burden), the highest the price (in terms of tumor recurrence rates). ${ }^{3}$

The path toward a more liberal indication of LT in HCC may be walked with leaden feet. A deeper understanding on HCC biology is still needed, and it is central to implement surrogate markers of tumor aggressiveness in clinical practice, in order to ensure that selected patients will remain $\mathrm{HCC}$ recurrence-free after $\mathrm{LT}^{7}{ }^{7}$ In the present review, surrogate markers of tumor biological aggressiveness are critically evaluated as potential tools to select candidates for LT, either alone or in combination with existing radiological criteria. In addition, the potential role of liquid biopsy in this clinical scenario is analyzed to delineate future directions.

\section{Serum soluble markers}

Tumor burden, as assessed by radiological techniques, is a poor surrogate of $\mathrm{HCC}$ biological aggressiveness: large or multiple HCCs are not always associated with aggressive biological behavior and conversely some patients with small uninodular lesions may show histological features indicating an evolved invasive phenotype. Serum proteins produced by the tumor may provide additional information about its biological behavior (Table 1). The combination of these biomarkers with radiological assessment may result in a more rational approach to select candidates for $\mathrm{LT}^{8}$

\section{Alpha-fetoprotein (AFP)}

AFP is a glycoprotein produced by the liver during fetal life and by a variety of tumors including HCC. ${ }^{9}$ Serum AFP levels are widely available in clinical practice and they have been traditionally considered a surrogate of tumor burden. ${ }^{10}$ However, AFP is over-expressed in only $60 \%-70 \%$ of patients with $\mathrm{HCC}$, while false positives may occur in acute and chronic hepatitis from different etiologies. ${ }^{11}$ As a conse-

Table I Summary of serum biomarkers with prognostic capacity in patients with hepatocellular carcinoma awaiting liver transplantation

\begin{tabular}{|c|c|c|c|c|c|}
\hline Biomarker & Validation status & Selected references & $\mathbf{n}$ & Proposed threshold & Prognostic impact \\
\hline AFP & $\begin{array}{l}\text { Prospectively and } \\
\text { externally validated }\end{array}$ & $\begin{array}{l}\text { Vibert et } \mathrm{al}^{63} \\
\text { Lai et al } \\
\text { Mailey et } \mathrm{al}^{14} \\
\text { Duvoux et } \mathrm{a}^{24} \\
\text { Berry and loannou }{ }^{18}\end{array}$ & \begin{tabular}{|l|}
153 \\
432 \\
2,253 \\
972 \\
\\
45,267
\end{tabular} & $\begin{array}{l}\Delta 15 \mathrm{ng} / \mathrm{mL} / \mathrm{month} \\
\geq 400 \mathrm{ng} / \mathrm{mL} \\
>1,000 \mathrm{ng} / \mathrm{mL} \\
>65 \mathrm{ng} / \mathrm{mL}\end{array}$ & $\begin{array}{l}\text { Decreased survival } \\
\text { Tumor progression } \\
\text { Decreased overall survival } \\
\text { Higher tumor recurrence } \\
\text { Microvascular invasion } \\
\text { Higher mortality }\end{array}$ \\
\hline DCP & $\begin{array}{l}\text { Insufficient external } \\
\text { validation }\end{array}$ & $\begin{array}{l}\text { Taketomi et } \mathrm{a}^{43} \\
\text { Takada and Uemoto } \\
\text { Kim et a }{ }^{32} \\
\text { Shindoh et } \mathrm{al}^{39} \\
\text { Ma et a } \mathrm{l}^{37}\end{array}$ & $\begin{array}{l}90 \\
136 \\
180 \\
124 \\
117\end{array}$ & $\begin{array}{l}<300 \mathrm{mAU} / \mathrm{mL} \\
\leq 400 \mathrm{mAU} / \mathrm{mL} \\
\geq 200 \mathrm{mAU} / \mathrm{mL} \\
>450 \mathrm{mAU} / \mathrm{mL} \\
>40 \mathrm{mAU} / \mathrm{mL}\end{array}$ & $\begin{array}{l}\text { Lower recurrence rates } \\
\text { Increased survival } \\
\text { Microvascular invasion }\end{array}$ \\
\hline AFP-L3 & $\begin{array}{l}\text { Insufficient external } \\
\text { validation }\end{array}$ & Cheng et al ${ }^{58}$ & 4,465 & No agreement & Decreased survival \\
\hline OPN & Preclinical stage & Sieghart et $\mathrm{al}^{61}$ & 125 & No agreement & Higher recurrence rates \\
\hline NLR & $\begin{array}{l}\text { Insufficient external } \\
\text { validation }\end{array}$ & $\begin{array}{l}\text { Halazun et } \mathrm{al}^{45} \\
\text { Limaye et } \mathrm{al}^{46} \\
\text { Xiao et al }{ }^{47}\end{array}$ & $\begin{array}{l}150 \\
160 \\
280\end{array}$ & $\begin{array}{l}\geq 5 \\
\geq 4\end{array}$ & $\begin{array}{l}\text { Decreased survival } \\
\text { Higher recurrence rates }\end{array}$ \\
\hline CTCs & $\begin{array}{l}\text { Insufficient external } \\
\text { validation }\end{array}$ & $\begin{array}{l}\text { Xue et } \mathrm{al}^{136} \\
\text { Sun et } \mathrm{al}^{129}\end{array}$ & $\begin{array}{l}40 \\
123\end{array}$ & $\begin{array}{l}\leq 5 / 7.5 \mathrm{~mL} \\
\geq 2 / 7.5 \mathrm{~mL}\end{array}$ & $\begin{array}{l}\text { Increased recurrence-free } \\
\text { survival } \\
\text { Lower recurrence rates }\end{array}$ \\
\hline cfDNA & Preclinical stage & $\begin{array}{l}\text { Ono et a }\left.\right|^{139} \\
\text { Liao et } a^{140}\end{array}$ & 46 & No agreement & $\begin{array}{l}\text { Microvascular invasion } \\
\text { Decreased recurrence-free } \\
\text { survival }\end{array}$ \\
\hline
\end{tabular}

Abbreviations: AFP-L3, Lens culinaris agglutinin fraction of alpha-fetoprotein; AFP, alpha-fetoprotein; CTC, circulating tumor cells; DCP, Des-y-carboxyprothrombin; NLR, neutrophil-to-lymphocyte ratio; OPN, osteopontin; cfDNA, cell-free DNA. 
quence, international guidelines have removed serum AFP from the current HCC screening and diagnostic algorithms. ${ }^{1,12}$ The actual value of serum AFP relies on its prognostic capacity ${ }^{10}$ : increased AFP is associated with histologically poor tumor differentiation, microvascular invasion, increased postoperative tumor recurrence rates and reduced overall survival after LT. $^{13-17}$

A large observational study $(n=45,267)$ showed that patients exceeding Milan criteria had a posttransplant survival comparable to patients who underwent LT for nonmalignant indications if preoperative serum AFP was $<15 \mathrm{ng} / \mathrm{mL}$, achieving a $72 \%$ 6-year survival rates. ${ }^{18}$ Unfortunately, such reduced AFP levels are uncommon among patients outside Milan criteria. A higher threshold of AFP $<400 \mathrm{ng} / \mathrm{mL}$ may be acceptable to rescue more patients exceeding Milan criteria for LT according to two independent observational studies including 2,419 patients. ${ }^{14,19}$ Indeed, pre-LT AFP $\geq 400 \mathrm{ng} /$ $\mathrm{mL}$ is indicative of poor prognosis, doubling posttransplant recurrence rates as well as dropout from the waiting list due to tumor progression or cancer-related symptoms..$^{14,19-22}$ Moreover, in clinical practice, patients with AFP levels $>1,000 \mathrm{ng} /$ $\mathrm{mL}$ should be carefully evaluated and LT may be discouraged because of an unacceptable risk of HCC recurrence, even if they fulfill Milan criteria. ${ }^{23,24}$ In some LT institutions, these patients are evaluated as potential candidates only if AFP decreases below $400 \mathrm{ng} / \mathrm{mL}$ after local ablation in a stable fashion. ${ }^{9,25}$

\section{Des-y-carboxyprothrombin (DCP)}

Also known as prothrombin induced by vitamin $\mathrm{K}$ absence II (PIVKA-II), DCP is an abnormal form of prothrombin produced predominantly by HCC cells. ${ }^{26}$ According to a meta-analysis of 12 observational studies, DCP has a modest sensitivity (71\%) and specificity $(84 \%)^{27}$ for HCC diagnosis, ${ }^{28}$ which could be improved in combination with other biomarkers such as AFP. ${ }^{29-31}$ Increased DCP also indicates a more aggressive tumor phenotype, ${ }^{30,32}$ increased microvascular invasion rates, ${ }^{17,33-35}$ extrahepatic metastases ${ }^{36}$ and accelerated proliferation. ${ }^{37}$

DCP may be used to predict disease-free survival and overall survival after LT and is widely used in the Eastern world. ${ }^{38-40} \mathrm{DCP}>400 \mathrm{mAu} / \mathrm{mL}$ at inclusion on the waiting list was associated with a 5 -fold increased risk of posttransplant HCC recurrence. ${ }^{41}$ Unfortunately, these results have not been sufficiently validated. In combination with AFP $<300 \mathrm{ng} /$ $\mathrm{mL}$, DCP levels $<300 \mathrm{mAU} / \mathrm{mL}$ result in 5-year recurrencefree survival rates as high as $70 \%$, provided that total tumor diameter was $<10 \mathrm{~cm}$, and in the absence of macrovascular invasion or extrahepatic spreading. ${ }^{42}$ In Japan, the Kyushu University considered LT in patients with tumors $\leq 5 \mathrm{~cm}$ diameter and serum DCP $\leq 300 \mathrm{mAU} / \mathrm{mL}$, despite the number of nodules, achieving 5 -year overall survival rates of $83 \%{ }^{43}$ The Kyoto University proposed to restrict the number of nodules $(\leq 10)$ while increasing the DCP threshold to $\leq 400 \mathrm{mAU} / \mathrm{mL}$, again with excellent results: 5 -year survival rates of $87 \%$ and $\mathrm{HCC}$ recurrence rates below $3 \%{ }^{44}$

\section{Inflammatory markers}

Neutrophil-to-lymphocyte ratio (NLR), ${ }^{45-48}$ platelet-tolymphocyte ratio (PLR $)^{49}$ and, more recently, lymphocyteto-monocyte ratio (LMR) ${ }^{50}$ have been proposed as useful biomarkers to predict posttransplant HCC recurrence, overall survival and/or dropout from the waiting list. Reduced baseline NLR was significantly associated with better overall survival (HR $=1.80, P<0.00001)$ and recurrence-free survival (HR $=2.23, P<0.00001)$ after LT, according to a meta-analysis of 90 studies including 20,475 patients. ${ }^{51}$ Conversely, NLR $\geq 5$ was a significant predictor of poor disease-free survival (HR $=19.98, P=0.005)$ in patients within Milan criteria. ${ }^{45}$ On the other hand, a high PLR was significantly associated with worse overall survival $(\mathrm{HR}=1.60, P=0.0005)$ in a metaanalysis of 10 studies involving 2,315 patients. ${ }^{49}$ Moreover, a pretransplant PLR $\geq 125$ was associated with significantly more aggressive tumors. ${ }^{52} \mathrm{~A}$ more recent study has addressed LMR in LDLT candidates with HCC, showing that a low LMR may be an independent predictor of worse prognosis, particularly among patients beyond the Milan criteria. ${ }^{50}$

C-reactive protein (CRP) is elevated in many clinical conditions including infections, autoimmune or inflammatory diseases and cancer. In HCC patients, CRP $\geq 10 \mathrm{mg} / \mathrm{dL}$ has been linked with reduced overall survival and recurrence-free survival, ${ }^{53}$ and it seems to correlate with vascular invasion rates ${ }^{53-56}$ However, it is unlikely that CRP may become part of therapeutic decisions in HCC patients, either alone or in combination with other biomarkers, given its insufficient specificity.

\section{Other serum markers}

The Lens culinaris agglutinin fraction of alpha-fetoprotein (AFP-L3) is a variant of AFP based on the sugar chain structure. AFP-L3 is observed mainly in malignant cells ${ }^{36}$ and it correlates with tumor size,${ }^{57}$ thus resulting particularly useful in HCC patients who show normal serum AFP. Elevated AFP-L3 was an independent predictor of decreased overall survival and disease-free survival in a meta-analysis of 15 observational studies including 4,465 patients. ${ }^{58}$ Unlike other 
biomarkers described above, AFP-L3 is not directly associated with vascular invasion, and its potential role to select candidates for LT remains to be explored.

Osteopontin (OPN) is a protein expressed by transformed malignant epithelial cells from several tumors. It has been suggested as an useful independent diagnostic tool in HCC. ${ }^{59}$ OPN is over-expressed in advanced tumors, particularly in those with poor histological differentiation, ${ }^{60}$ and it has been proposed as an independent predictor of tumor recurrence and survival in patients beyond Milan criteria undergoing LT. ${ }^{61}$ Although promising, optimal thresholds remain to be determined and further validated.

\section{Behavior of the HCC on the waiting list \\ Dynamic changes in AFP}

AFP progressive elevation is a surrogate marker of tumor aggressiveness, foreseeing satellite nodules, vascular invasion and extrahepatic spreading even in small uninodular HCC. As a rule of thumb, dynamic changes in AFP are more reliable than a preoperative single value. ${ }^{18,22}$ AFP slope $>15 \mathrm{ng} /$ $\mathrm{mL} / \mathrm{month}$ after locoregional ablative therapy (LRT) is an independent predictor of HCC post-LT recurrence, ${ }^{62}$ and it is associated with decreased overall survival (77\% vs $54 \%$ at 5 years; $P<0.0001)^{62,63}$ and recurrence-free survival (74\% vs $47 \%$ at 5 years; $P=0.01) .{ }^{63}$ There have been several attempts to include AFP as part of a continuous score for patients with HCC awaiting LT. The HCC-MELD score aims to be a continuous score of survival benefit according to liver function and AFP level, calibrated to the survival benefit of non-HCC patients by MELD (for instance, an HCC-MELD score of 20 would calibrate to the survival benefit of a biological MELD score of 20). ${ }^{64} \mathrm{HCC}-\mathrm{MELD}$ was designed as a system to give additional, nonarbitrary points based on transplant survival benefit calculation, and it has been independently validated to predict posttransplantation outcome. ${ }^{65}$ Another variation named deMELD score (where "de" stands for "dropout equivalent"), comprising tumor size, number of nodules and AFP value, aims to provide a dynamic and more accurate assessment of dropout on waiting list. ${ }^{66,67}$ Further prospective international validation is needed before these scores are implemented in routine clinical practice.

\section{Radiological response to locoregional therapies}

The purpose of bridging LRT is to prevent tumor progression and dropout from the waiting list and also to reduce the risk of posttransplant HCC recurrence. ${ }^{68-70}$ Radiofrequency ablation (RFA) and trans-arterial chemoembolization (TACE) are the most frequent modalities of LRT, and there is no definitive evidence that one is superior to the other. ${ }^{71}$ The use of bridging LRT is highly recommended when the expected length within the waiting list is longer than 6 months, ${ }^{1}$ but in clinical practice the vast majority of patients undergo LRT unless technically unfeasible.

In this context, the absence of radiological response to LRT is indicative of increased risk of HCC recurrence after LT. ${ }^{68,72,73}$ Successful downstaging has been associated with excellent posttransplantation outcomes, achieving a 4-year intention-to-treat survival over $92 \% .^{74}$ In a German study assessing TACE for patients awaiting LT $(n=50)$, increased tumor recurrence rates were found in those who showed disease progression despite LRT $(64.6 \%$ vs $5.5 \%, P=0.001){ }^{75}$ This is the rationale for the "ablate and wait" strategy, according to which a waiting period of at least 3 months after LRT would be mandatory in order to select those patients with a low risk of recurrence, as a partially treated tumor with favorable biology would not progress in a short observation time. ${ }^{72,74,76-78}$ The increasing evidence regarding this issue led to a recent change of the allocation system in the United States, which now incorporates a 6-month delay before granting MELD exception points in order to identify higher-risk HCC patients. ${ }^{79}$

\section{Tissue biomarkers}

Liver biopsy is not routinely performed for HCC diagnosis in clinical practice due to the precision of dynamic imaging techniques and to the potential risk of biopsy-related complications including tumor seeding. ${ }^{80,81}$ However, the emerging role of tissue biomarkers to assess tumor biological behavior and to predict response to targeted therapies is changing this scenario.

Vascular invasion is a critical hallmark in HCC spreading, both within and outside the liver, and indicates an evolved tumor phenotype. Microvascular invasion is defined as a tumor emboli within a vascular space (either portal or suprahepatic), not detectable by radiological techniques, and forms the most reliable predictor of tumor recurrence, able to double the risk after liver resection and triple the risk after $\mathrm{LT}^{82}$ Unfortunately, microvascular invasion may only be evaluated in the whole HCC specimen and cannot be ruled out by conventional needle biopsy. This fact limits its applicability to select candidates for LT. However, patients who undergo liver resection and show microvascular invasion may be considered for LT, given that tumor recurrence would occur in up to $70 \%$ of cases otherwise. There are other classical 
histological features of HCC related to worse prognosis and able to be detected in a liver biopsy specimen. Moderatepoor tumor differentiation according to the Edmonson scale is associated with more aggressive tumors. ${ }^{3}$ The group from the University of Toronto considered patients above Milan criteria for LT without any restriction on number/diameter of nodules if poor differentiation is ruled out in a liver biopsy of the dominant nodule. ${ }^{83}$ In addition, certain HCC histological subtypes such as sarcomatoid ${ }^{84}$ or macrotrabecular ${ }^{85}$ are associated with poorly differentiated grades, higher rates of vascular invasion and reduced overall survival.

Glypican-3 (GPC-3) has been identified as a critical tissue marker of HCC. ${ }^{86}$ It is expressed by more than $90 \%$ of AFP-negative tumors, ${ }^{87}$ while it is not found on cirrhotic and non-cirrhotic adult liver tissues. ${ }^{88}$ GPC-3 staining pattern, despite not correlating with tumor differentiation, ${ }^{88}$ is an independent prognostic factor for reduced disease-free survival in patients with $\mathrm{HCV}$ infection. ${ }^{89-91}$ Many other biomarkers have been associated with either poorer survival or aggressive tumor behavior, ${ }^{92}$ including lysosomal protein transmembrane 4 beta-35 (LAPTM4B-35), ${ }^{93}$ focal adhesion kinase (FAK), ${ }^{94}$ fascin (FSCN1), ${ }^{95}$ histone deacetylases,${ }^{96}$ CD133, ${ }^{97}$ nucleophosmin (NPM) ${ }^{98}$ basic leucine zipper transcription factor ATF-like 2 (BATF2), ${ }^{99}$ programmed cell death ligands (PDL), ${ }^{100}$ E-cadherin, ${ }^{101}$ Dickkopf-1 (DKK1) $)^{102,103}$ and OPN. ${ }^{104,105}$ However, the true potential of these biomarkers requires further evaluation.

\section{8FDG-Positron emission tomography (PET)}

Liver tissue highlighted by ${ }^{18} \mathrm{FDG}$ displays poor grades of differentiation $(\mathrm{RR}=9.5)$ and microvascular invasion $(\mathrm{RR}$ =6.4). ${ }^{106,107} \mathrm{~A}$ positive ${ }^{18}$ FDG-PET has been significantly associated with higher risk of post-LT recurrence $(\mathrm{HR}=3.95$, $P=0.024)$ as well as reduced disease-free survival ( $87 \%$ vs $57 \%$ at 3 years, $P<0.001) .{ }^{108-110}$ In addition, patients outside Milan criteria with a negative PET showed no statistically significant differences in terms of 5-year recurrence-free survival rates when compared to patients within Milan criteria $(81 \%$ vs $86.2 \%, P=0.002),{ }^{111}$ while a PET positive became an independent predictor of dropout from the waiting list (HR $=5.7, P=0.01$ ), providing additional information to elevated serum AFP. ${ }^{112}$

\section{Liquid biopsy}

The detection of tumor byproducts in the bloodstream, also known as liquid biopsy, is a rapidly evolving research field that has engaged the scientific community in recent years.
Indeed, identifying circulating-tumor-cells (CTC) ${ }^{113}$ or cell-free DNAs (cfDNA) ${ }^{114}$ in the peripheral circulation is a noninvasive and reproducible procedure that could potentially provide dynamic information regarding tumor activity. ${ }^{115-118}$ The quantitative and qualitative assessment of circulating tumor-derived products is attractive as a research field, not only for screening or diagnosis, but also to select candidates for LT and prioritize them within the waiting list.

\section{Circulating tumor cells}

HCC recurrence after LT implies that remnant tumor cells are left behind after surgery and remain in the bloodstream unnoticed to the surveillance of the immune system (which is impaired by the use of immunosuppressive drugs). ${ }^{119}$ The assessment of CTCs before LT is an appealing research field with a huge translational potential. Theoretically, patients with persistently increased number of CTCs despite LRT would be removed from the waiting list and offered alternative therapies, and conversely patients with a complete clearance of CTCs after LRT would be perfect candidates to be included within the waiting list and further prioritized irrespective of their tumor burden.

CTCs have been extensively evaluated in different types of cancer. In order to be implemented in HCC clinical practice, detection techniques of CTCs may be sufficiently accurate, reproducible, affordable and without any significant intra- and interobserver variability. ${ }^{120}$ In addition, it would be highly desirable that the methodology would allow for an effective recovery of viable CTCs for their ulterior characterization and culture. However, CTCs are scarce in peripheral blood, lost into millions of leukocytes and erythrocytes, thus hampering their identification by using conventional flow cytometry. There is no perfect method for CTCs detection, and usually several technologies are combined to counteract each other disadvantages. ${ }^{120-122}$ Two assays have emerged and launched into the market with some supporting clinical evidence for identification, isolation and enumeration of CTCs in HCC, namely, CellSearch ${ }^{\circledR}$ (Veridex Inc.), which is the only one approved by the FDA, and Isoflux (Fluxion Biosciences), which claims for an improved sensitivity ${ }^{123}$ and isolation capacity. Both technologies are based on the detection of epithelial cellular adhesion molecule (EpCAM) positive/CD45 negative (EpCAM ${ }^{+} / \mathrm{CD}^{-} 5^{-}$) cells. EpCAM is a transmembrane glycoprotein that is present in epithelial cells and in some types of cancer cells, including HCC. ${ }^{124}$ In the tumoral tissue, EpCAM ${ }^{+}$cells have been correlated with vascular invasion, multinodular tumors and reduced overall survival, ${ }^{113,125,126}$ being more frequent in the tumor invasion edge. 
In the bloodstream, CTCs are much increased in patients with microvascular invasion, macrovascular invasion and multinodular disease ${ }^{126}$ leading to poor overall survival. ${ }^{127,128}$ Persistence of CTCs after liver resection has been associated with early HCC recurrence by using the CellSearch System ${ }^{\circledR}$ : a CTCs $\geq 2$ count was identified as an independent prognostic factor in multivariate analysis, even in subgroups with normal AFP and low-risk histological features. ${ }^{129}$ Similar findings have been reproduced by other research groups but without an agreement on the optimal threshold of CTCs to predict tumor recurrence. ${ }^{18,130-132}$ A CTCs count slope is also associated with disease progression, ${ }^{133}$ and the persistence of CTCs after a potentially curative therapy may be an independent prognostic factor. ${ }^{134,135}$ In patients undergoing LT, an independent association between recurrence-free survival after LT and preoperative CTCs count was demonstrated. ${ }^{136}$ Even in patients with low AFP levels, CTCs count still predicted outstanding recurrence rates. ${ }^{136}$ Nevertheless, no significant association was observed between HCC recurrence after LT and total CTCs change or CTCs subtype in another study, ${ }^{137}$ probably related to its insufficient statistical power due to the small sample size.

A number of issues remain to be solved before implementing CTCs as a biological marker in HCC patients undergoing LT: 1) different methodologies to detect CTCs may be compared face to face in order to identify the most accurate to become the gold standard; 2) an automated methodology for CTC counting may be implemented to reduce interobserver variability while decreasing enumeration length and 3) new prospective, multicenter and well-designed studies need to be conducted in LT candidates and further independently validated.

\section{Cell-free DNA}

Detection of cfDNA is another modality of liquid biopsy that is associated with tumor burden, microvascular invasion and extrahepatic metastasis, ${ }^{138-140}$ thus identifying disease progression even in cases of negative AFP. It has been shown to be a highly specific biomarker, ${ }^{141,142}$ more frequently detected in patients with larger tumors, poor histological differentiation and associated with reduced overall survival as well as early tumor recurrence after curative resection. ${ }^{143-145}$ Moreover, cfDNA allows to analyze HCC genetic and epigenetic profile, ${ }^{146}$ as it resembles the matched primary tumor. ${ }^{140}$ cfDNA is also easier to obtain after LRT, and its quantification mirrors radiological response as well as disease progression. ${ }^{139}$
However, HCC may suffer heterogenous molecular transformations, even in the presence of similar histopathological findings, ${ }^{147}$ which would make it unlikely to identify every relevant mutation in a single blood sample. ${ }^{148}$ Targeted deep sequencing may allow to circumvent intratumor heterogeneity, ${ }^{149}$ identifying mutations which could act as new therapeutic targets. The expression or absence of cfDNA related to EpCAM and AFP defined up to four HCC subtypes, each one displaying distinct tumor features and reflecting different hepatic lineages, being $\mathrm{EpCAM}^{+} / \mathrm{AFP}^{-}$tumors significantly correlated with lower rates of portal vein invasion and improved overall prognosis. Conversely, tumors with cfDNA encoding AFP were linked to worse prognosis. ${ }^{124}$ These findings are mainly exploratory but they may impact the decision-making algorithm in the future.

\section{Conclusion}

Selected patients outside Milan criteria but showing favorable tumor behavior may be acceptable candidates for LT. Surrogate markers of tumor biology are able to predict outcomes after LT and may be incorporated as part of the decision-making algorithm. Among them, only serum AFP is sufficiently validated to make practical recommendations. Raising AFP over $400 \mathrm{ng} / \mathrm{mL}$ despite LRT should motivate a deep evaluation of tumor burden before including a patient in the waiting list. If AFP persists $>1,000 \mathrm{ng} / \mathrm{mL}$, LT should be discouraged, even in patients within Milan criteria. There are other serum biomarkers such as DCP, AFP-L3 and NLR, which are already standardized and available in clinical practice, but they deserve further validation to define thresholds and to validate their accuracy before being implemented. Tissue biomarkers are hampered by the need of pre-LT liver biopsy, which is not routinely performed. Liquid biopsy allows detecting and enumerating CTCs, and even to analyze DNA mutations, thus offering direct and dynamic information concerning tumor biological behavior. Although there are still some technical caveats to be solved, liquid biopsy will probably reshape the management of $\mathrm{HCC}$ in the upcoming years.

\section{Disclosure}

The authors report no conflicts of interest in this work.

\section{References}

1. European Association for the Study of the Liver. Electronic address: easloffice@easloffice.eu; European Association for the Study of the Liver. EASL Clinical Practice Guidelines: management of hepatocellular carcinoma. J Hepatol. 2018;69(1):182-236. 
2. European Association for the Study of the Liver. Electronic address: easloffice@easloffice.eu. EASL Clinical Practice Guidelines: liver transplantation. J Hepatol. 2016;64(2):433-485.

3. Mazzaferro V, Llovet JM, Miceli R, et al. Predicting survival after liver transplantation in patients with hepatocellular carcinoma beyond the Milan criteria: a retrospective, exploratory analysis. Lancet Oncol. 2009;10(1):35-43.

4. European Association for the Study of the Liver. Electronic address: easloffice@easloffice.eu, European Association for the Study of the Liver. EASL recommendations on treatment of hepatitis C 2018. J Hepatol. 2018;69(2):461-511.

5. Herrero JI, Sangro B, Pardo F, et al. Liver transplantation in patients with hepatocellular carcinoma across Milan criteria. Liver Transpl. 2008;14(3):272-278.

6. Yao FY, Ferrell L, Bass NM, et al. Liver transplantation for hepatocellular carcinoma: expansion of the tumor size limits does not adversely impact survival. Hepatology. 2001;33(6):1394-1403.

7. Guerrero-Misas M, Rodríguez-Perálvarez M, de La Mata M. Strategies to improve outcome of patients with hepatocellular carcinoma receiving a liver transplantation. World J Hepatol. 2015;7(4):649-661.

8. Tsuchiya N, Sawada Y, Endo I, Saito K, Uemura Y, Nakatsura T. Biomarkers for the early diagnosis of hepatocellular carcinoma. World $J$ Gastroenterol. 2015;21(37):10573-10583.

9. Charrière B, Maulat C, Suc B, Muscari F. Contribution of alphafetoprotein in liver transplantation for hepatocellular carcinoma. World J Hepatol. 2016;8(21):881-890.

10. Chan SL, Mo FK, Johnson PJ, et al. New utility of an old marker: serial alpha-fetoprotein measurement in predicting radiologic response and survival of patients with hepatocellular carcinoma undergoing systemic chemotherapy. J Clin Oncol. 2009;27(3):446-452.

11. Johnson PJ. The role of serum alpha-fetoprotein estimation in the diagnosis and management of hepatocellular carcinoma. Clin Liver Dis. 2001;5(1):145-159.

12. Bruix J, Sherman M, American association for the study of liver diseases Management of hepatocellular carcinoma: an update. Hepatology. 2011;53(3):1020-1022.

13. Toso C, Asthana S, Bigam DL, Shapiro AM, Kneteman NM. Reassessing selection criteria prior to liver transplantation for hepatocellular carcinoma utilizing the Scientific Registry of Transplant Recipients database. Hepatology. 2009;49(3):832-838.

14. Mailey B, Artinyan A, Khalili J, et al. Evaluation of absolute serum $\alpha$-fetoprotein levels in liver transplant for hepatocellular cancer. Arch Surg. 2011;146(1):26-33.

15. Muscari F, Guinard JP, Kamar N, Peron JM, Otal P, Suc B. Impact of preoperative $\alpha$-fetoprotein level on disease-free survival after liver transplantation for hepatocellular carcinoma. World J Surg. 2012;36(8):1824-1831.

16. Ma WJ, Wang HY, Teng LS. Correlation analysis of preoperative serum alpha-fetoprotein (AFP) level and prognosis of hepatocellular carcinoma (HCC) after hepatectomy. World J Surg Oncol. 2013;11:212.

17. Yamashita YI, Imai K, Yusa T, et al. Microvascular invasion of single small hepatocellular carcinoma $\leq 3 \mathrm{~cm}$ : predictors and optimal treatments. Ann Gastroenterol Surg. 2018;2(3):197-203.

18. Berry K, Ioannou GN. Serum alpha-fetoprotein level independently predicts posttransplant survival in patients with hepatocellular carcinoma. Liver Transpl. 2013;19(6):634-645.

19. Toso C, Meeberg G, Hernandez-Alejandro R, et al. Total tumor volume and alpha-fetoprotein for selection of transplant candidates with hepatocellular carcinoma: a prospective validation. Hepatology. 2015;62(1):158-165.

20. Ciccarelli O, Lai Q, Goffette P, et al. Liver transplantation for hepatocellular cancer: UCL experience in 137 adult cirrhotic patients. Alpha-foetoprotein level and locoregional treatment as refined selection criteria. Transpl Int. 2012;25(8):867-875.

21. Sapisochin G, Goldaracena N, Laurence JM, et al. The extended Toronto criteria for liver transplantation in patients with hepatocellular carcinoma: a prospective validation study. Hepatology. 2016;64(6):2077-2088.
22. Lai Q, Iesari S, Melandro F, Mennini G, Rossi M, Lerut J. The growing impact of alpha-fetoprotein in the field of liver transplantation for hepatocellular cancer: time for a revolution. Transl Gastroenterol Hepatol. 2017;2:72

23. Hameed B, Mehta N, Sapisochin G, Roberts JP, Yao FY. Alpha-fetoprotein level $>1000 \mathrm{ng} / \mathrm{mL}$ as an exclusion criterion for liver transplantation in patients with hepatocellular carcinoma meeting the Milan criteria. Liver Transpl. 2014;20(8):945-951.

24. Duvoux C, Roudot-Thoraval F, Decaens T, et al. Liver transplantation for hepatocellular carcinoma: a model including $\alpha$-fetoprotein improves the performance of Milan criteria. Gastroenterology. 2012;143(4):986-994

25. Jang JW, You CR, Kim CW, et al. Benefit of downsizing hepatocellular carcinoma in a liver transplant population. Aliment Pharmacol Ther. 2010;31(3):415-423.

26. Liebman HA, Furie BC, Tong MJ, et al. Des-gamma-carboxy (abnormal) prothrombin as a serum marker of primary hepatocellular carcinoma. N Engl J Med. 1984;310(22):1427-1431.

27. Zhu R, Yang J, Xu L, et al. Diagnostic performance of des- $\gamma$-carboxy prothrombin for hepatocellular carcinoma: a meta-analysis. Gastroenterol Res Pract. 2014;2014:529314.

28. Xing H, Yan C, Cheng L, et al. Clinical application of protein induced by vitamin $\mathrm{K}$ antagonist-II as a biomarker in hepatocellular carcinoma. Tumour Biol. 2016;1;37(12):15447-56.

29. Song P, Feng X, Zhang K, et al. Perspectives on using des- $\gamma$ carboxyprothrombin (DCP) as a serum biomarker: facilitating early detection of hepatocellular carcinoma in China. Hepatobiliary Surg Nutr. 2013;2(4):227-231.

30. Meguro M, Mizuguchi T, Nishidate T, et al. Prognostic roles of preoperative $\alpha$-fetoprotein and des- $\gamma$-carboxy prothrombin in hepatocellular carcinoma patients. World J Gastroenterol. 2015;21(16):4933-4945.

31. Lim TS, Kim DY, Han KH, et al. Combined use of AFP, PIVKA-II, and AFP-L3 as tumor markers enhances diagnostic accuracy for hepatocellular carcinoma in cirrhotic patients. Scand J Gastroenterol.2016;51(3):344-353.

32. Kim JM, Hyuck C, Kwon D, et al. Protein induced by vitamin K antagonist-II (PIVKA-II) is a reliable prognostic factor in small hepatocellular carcinoma. World J Surg. 2013;37(6):1371-1378.

33. Iguchi T, Shirabe K, Aishima S, et al. New pathologic stratification of microvascular invasion in hepatocellular carcinoma: predicting prognosis after living-donor liver transplantation. Transplantation. 2015;99(6):1236-1242.

34. Shirabe K, Itoh S, Yoshizumi T, et al. The predictors of microvascular invasion in candidates for liver transplantation with hepatocellular carcinoma-with special reference to the serum levels of des-gammacarboxy prothrombin. J Surg Oncol. 2007;95(3):235-240.

35. Poté N, Cauchy F, Albuquerque M, et al. Performance of PIVKA-II for early hepatocellular carcinoma diagnosis and prediction of microvascular invasion. J Hepatol. 2015;62(4):848-854.

36. Carr BI, Kanke F, Wise M, Satomura S. Clinical evaluation of lens culinaris agglutinin-reactive alpha-fetoprotein and des-gamma-carboxy prothrombin in histologically proven hepatocellular carcinoma in the United States. Dig Dis Sci. 2007;52(3):776-782.

37. Ma XL, Zhu J, Wu J, et al. Significance of PIVKA-II levels for predicting microvascular invasion and tumor cell proliferation in Chinese patients with hepatitis B virus-associated hepatocellular carcinoma. Oncol Lett. 2018;15(6):8396-8404.

38. Todo S, Furukawa H, Tada M, Japanese Liver Transplantation Study Group. Extending indication: role of living donor liver transplantation for hepatocellular carcinoma. Liver Transpl. 2007;13(11 Suppl 2):S48-S54.

39. Shindoh J, Sugawara Y, Nagata R, et al. Evaluation methods for pretransplant oncologic markers and their prognostic impacts in patient undergoing living donor liver transplantation for hepatocellular carcinoma. Transpl Int. 2014;27(4):391-398.

40. Pommergaard HC, Burcharth J, Rosenberg J, Rasmussen A. Serologic and molecular biomarkers for recurrence of hepatocellular carcinoma after liver transplantation: a systematic review and meta-analysis. Transplant Rev (Orlando). 2016;30(3):171-177. 
41. Lai Q, Iesari S, Levi Sandri GB, Lerut J. Des-gamma-carboxy prothrombin in hepatocellular cancer patients waiting for liver transplant: a systematic review and meta-analysis. Int J Biol Markers. 2017;32(4):e370-e374.

42. Lee HW, Song GW, Lee SG, et al. Patient selection by tumor markers in liver transplantation for advanced hepatocellular carcinoma. Liver Transpl. 2018;24(9):1243-1251.

43. Taketomi A, Sanefuji K, Soejima Y, et al. Impact of des-gammacarboxy prothrombin and tumor size on the recurrence of hepatocellular carcinoma after living donor liver transplantation. Transplantation. 2009;87(4):531-537.

44. Takada Y, Uemoto S. Liver transplantation for hepatocellular carcinoma: the Kyoto experience. J Hepatobiliary Pancreat Sci. 2010;17(5):527-532.

45. Halazun KJ, Hardy MA, Rana AA, et al. Negative impact of neutrophillymphocyte ratio on outcome after liver transplantation for hepatocellular carcinoma. Ann Surg. 2009;250(1):141-151.

46. Limaye AR, Clark V, Soldevila-Pico C, et al. Neutrophil-lymphocyte ratio predicts overall and recurrence-free survival after liver transplantation for hepatocellular carcinoma. Hepatol Res. 2013;43(7):757-764.

47. Xiao GQ, Liu C, Liu DL, Yang JY, Yan LN. Neutrophil-lymphocyte ratio predicts the prognosis of patients with hepatocellular carcinoma after liver transplantation. World J Gastroenterol. 2013;19(45):8398-8407.

48. Lai Q, Castro Santa E, Rico Juri JM, Pinheiro RS, Lerut J. Neutrophil and platelet-to-lymphocyte ratio as new predictors of dropout and recurrence after liver transplantation for hepatocellular cancer. Transpl Int. 2014;27(1):32-41.

49. Zhao Y, Si G, Zhu F, et al. Prognostic role of platelet to lymphocyte ratio in hepatocellular carcinoma: a systematic review and meta-analysis. Oncotarget. 2017;8(14):22854-22862.

50. Mano Y, Yoshizumi T, Yugawa K, et al. Lymphocyte-to-monocyte ratio is a predictor of survival after liver transplantation for hepatocellular carcinoma. Liver Transpl. 2018;24(11):1603-1611.

51. Qi X, Li J, Deng H, Li H, Su C, Guo X. Neutrophil-to-lymphocyte ratio for the prognostic assessment of hepatocellular carcinoma: a systematic review and meta-analysis of observational studies. Oncotarget. 2016;7(29):45283-45301.

52. Xia W, Ke Q, Wang Y, et al. Predictive value of pre-transplant platelet to lymphocyte ratio for hepatocellular carcinoma recurrence after liver transplantation. World J Surg Oncol. 2015;13:60.

53. Zheng Z, Zhou L, Gao S, Yang Z, Yao J, Zheng S. Prognostic role of $\mathrm{C}$-reactive protein in hepatocellular carcinoma: a systematic review and meta-analysis. Int J Med Sci. 2013;10(6):653-664.

54. An HJ, Jang JW, Bae SH, et al. Serum C-reactive protein is a useful biomarker for predicting outcomes after liver transplantation in patients with hepatocellular carcinoma. Liver Transpl. 2012;18(12):1406-1414.

55. Na GH, Kim DG, Han JH, et al. Inflammatory markers as selection criteria of hepatocellular carcinoma in living-donor liver transplantation. World J Gastroenterol. 2014;20(21):6594-6601.

56. Kim YK, Kim SH, Lee SD, Hong SK, Park SJ. Pretransplant serum levels of C-reactive protein predict prognoses in patients undergoing liver transplantation for hepatocellular carcinoma. Transplant Proc. 2015;47(3):686-693.

57. Choi JY, Jung SW, Kim HY, et al. Diagnostic value of AFP-L3 and PIVKA-II in hepatocellular carcinoma according to total-AFP. World J Gastroenterol. 2013;19(3):339-346.

58. Cheng J, Wang W, Zhang Y, et al. Prognostic role of pre-treatment serum AFP-L3\% in hepatocellular carcinoma: systematic review and meta-analysis. PLoS One. 2014;9(1):e87011.

59. Wan HG, Xu H, Gu YM, Wang H, Xu W, Zu MH. Comparison osteopontin vs AFP for the diagnosis of HCC: a meta-analysis. Clin Res Hepatol Gastroenterol. 2014;38(6):706-714.

60. Beckebaum S, Chen X, Sotiropoulos GC, et al. Role of osteopontin and CD44s expression for patients with hepatocellular carcinoma undergoing liver transplantation or resection. Transplant Proc. 2008;40(9):3182-3184.
61. Sieghart W, Wang X, Schmid K, et al. Osteopontin expression predicts overall survival after liver transplantation for hepatocellular carcinoma in patients beyond the Milan criteria. J Hepatol. 2011;54(1):89-97.

62. Lai Q, Avolio AW, Graziadei I, et al. Alpha-fetoprotein and modified response evaluation criteria in solid tumors progression after locoregional therapy as predictors of hepatocellular cancer recurrence and death after transplantation. Liver Transpl. 2013;19(10):1108-1118.

63. Vibert E, Azoulay D, Hoti E, et al. Progression of alphafetoprotein before liver transplantation for hepatocellular carcinoma in cirrhotic patients: a critical factor. Am J Transplant. 2010;10(1):129-137.

64. Vitale A, Volk ML, de Feo TM, et al. A method for establishing allocation equity among patients with and without hepatocellular carcinoma on a common liver transplant waiting list. J Hepatol. 2014;60(2):290-297.

65. Guerrini GP, Pinelli D, Marini E, et al. Value of HCC-MELD score in patients with hepatocellular carcinoma undergoing liver transplantation. Prog Transplant. 2018;28(1):63-69.

66. Toso C, Dupuis-Lozeron E, Majno P, et al. A model for dropout assessment of candidates with or without hepatocellular carcinoma on a common liver transplant waiting list. Hepatology. 2012;56(1):149-156.

67. Toso C, Majno P, Berney T, Morel P, Mentha G, Combescure C. Validation of a dropout assessment model of candidates with/without hepatocellular carcinoma on a common liver transplant waiting list. Transpl Int. 2014;27(7):686-695.

68. Cescon M, Cucchetti A, Ravaioli M, Pinna AD. Hepatocellular carcinoma locoregional therapies for patients in the waiting list. Impact on transplantability and recurrence rate. J Hepatol. 2013;58(3):609-618.

69. Shaker MK, Montasser IF, Sakr M, et al. Efficacy of loco-regional treatment for hepatocellular carcinoma prior to living donor liver transplantation: a report from a single center in Egypt. J Hepatocell Carcinoma. 2018;5:29-36.

70. Parikh ND, Waljee AK, Singal AG. Downstaging hepatocellular carcinoma: A systematic review and pooled analysis. Liver Transpl. 2015;21(9):1142-1152.

71. Györi GP, Felsenreich DM, Silberhumer GR, Soliman T, Berlakovich GA. Multimodality locoregional treatment strategies for bridging HCC patients before liver transplantation. Eur Surg. 2017;49(5):236-243.

72. Mazzaferro V. Squaring the circle of selection and allocation in liver transplantation for HCC: an adaptive approach. Hepatology. 2016;63(5):1707-1717.

73. Pommergaard HC, Rostved AA, Adam R, et al. Locoregional treatments before liver transplantation for hepatocellular carcinoma: a study from the European Liver Transplant Registry. Transpl Int. 2018;31(5):531-539.

74. Yao FY, Kerlan RK, Hirose R, et al. Excellent outcome following downstaging of hepatocellular carcinoma prior to liver transplantation: an intention-to-treat analysis. Hepatology. 2008;48(3):819-827.

75. Otto G, Herber S, Heise M, et al. Response to transarterial chemoembolization as a biological selection criterion for liver transplantation in hepatocellular carcinoma. Liver Transpl. 2006;12(8):1260-1267.

76. Roberts JP, Venook A, Kerlan R, Yao F. Hepatocellular carcinoma: Ablate and wait versus rapid transplantation. Liver Transpl. 2010;16(8):925-929.

77. Clavien PA, Lesurtel M, Bossuyt PM, et al. Recommendations for liver transplantation for hepatocellular carcinoma: an international consensus conference report. Lancet Oncol. 2012;13(1):e11-22.

78. Cillo U, Burra P, Mazzaferro V, et al. A multistep, consensus-based approach to organ allocation in liver transplantation: toward a "Blended Principle Model". Am J Transplant. 2015;15(10):2552-2561.

79. Marvin MR, Ferguson N, Cannon RM, Jones CM, Brock GN. MELDEQ: An alternative Model for End-Stage Liver Disease score for patients with hepatocellular carcinoma. Liver Transpl. 2015;21(5):612-622.

80. Yu SC, Lo DY, Ip CB, Liew CT, Leung TW, Lau WY. Does percutaneous liver biopsy of hepatocellular carcinoma cause hematogenous dissemination? An in vivo study with quantitative assay of circulating tumor DNA using methylation-specific real-time polymerase chain reaction. AJR Am J Roentgenol. 2004;183(2):383-385. 
81. Silva MA, Hegab B, Hyde C, Guo B, Buckels JA, Mirza DF. Needle track seeding following biopsy of liver lesions in the diagnosis of hepatocellular cancer: a systematic review and meta-analysis. Gut. 2008;57(11):1592-1596.

82. Rodríguez-Perálvarez M, Luong TV, Andreana L, Meyer T, Dhillon AP, Burroughs AK. A systematic review of microvascular invasion in hepatocellular carcinoma: diagnostic and prognostic variability. Ann Surg Oncol. 2013;20(1):325-339.

83. Dubay D, Sandroussi C, Sandhu L, et al. Liver transplantation for advanced hepatocellular carcinoma using poor tumor differentiation on biopsy as an exclusion criterion. Ann Surg. 2011;253(1):166-172.

84. Martins-Filho SN, Paiva C, Azevedo RS, Alves VAF. Histological grading of hepatocellular carcinoma-a systematic review of literature Front Med. 2017;4:193.

85. Ziol M, Poté N, Amaddeo G, et al. Macrotrabecular-massive hepatocellular carcinoma: A distinctive histological subtype with clinical relevance. Hepatology. 2018;68(1):103-112.

86. Jakubovic BD, Jothy S. Glypican-3: from the mutations of SimpsonGolabi-Behmel genetic syndrome to a tumor marker for hepatocellular carcinoma. Exp Mol Pathol. 2007;82(2):184-189.

87. Shafizadeh N, Ferrell LD, Kakar S. Utility and limitations of glypican-3 expression for the diagnosis of hepatocellular carcinoma at both ends of the differentiation spectrum. Mod Pathol. 2008;21(8):1011-1018.

88. Wang HL, Anatelli F, Zhai QJ, Adley B, Chuang ST, Yang XJ. Glypican-3 as a useful diagnostic marker that distinguishes hepatocellular carcinoma from benign hepatocellular mass lesions. Arch Pathol Lab Med. 2008;132(11):1723-1728.

89. Yorita K, Takahashi N, Takai H, et al. Prognostic significance of circumferential cell surface immunoreactivity of glypican-3 in hepatocellular carcinoma. Liver Int. 2011;31(1):120-131.

90. Shirakawa H, Suzuki H, Shimomura M, et al. Glypican-3 expression is correlated with poor prognosis in hepatocellular carcinoma. Cancer Sci. 2009;100(8):1403-1407.

91. Lo RC, Ng IO, Rc L, Io N. Hepatocellular tumors: immunohistochemical analyses for classification and prognostication. Chin J Cancer Res. 2011;23(4):245-253.

92. Ferrín G, Aguilar-Melero P, Rodríguez-Perálvarez M, Montero-Álvarez JL, de La Mata M. Biomarkers for hepatocellular carcinoma: diagnostic and therapeutic utility. Hepat Med. 2015;7:1-10.

93. Yang H, Xiong FX, Lin M, Yang Y, Nie X, Zhou RL. LAPTM4B-35 overexpression is a risk factor for tumor recurrence and poor prognosis in hepatocellular carcinoma. J Cancer Res Clin Oncol. 2010;136(2):275-281.

94. Itoh S, Maeda T, Shimada M, et al. Role of expression of focal adhesion kinase in progression of hepatocellular carcinoma. Clin Cancer Res. 2004;10(8):2812-2817.

95. Iguchi T, Aishima S, Umeda K, et al. Fascin expression in progression and prognosis of hepatocellular carcinoma. J Surg Oncol. 2009;100(7):575-579.

96. Rikimaru T, Taketomi A, Yamashita Y, et al. Clinical significance of histone deacetylase 1 expression in patients with hepatocellular carcinoma. Oncology. 2007;72(1-2):69-74.

97. Song W, Li H, Tao K, et al. Expression and clinical significance of the stem cell marker CD133 in hepatocellular carcinoma. Int J Clin Pract. 2008;62(8):1212-1218.

98. Yun JP, Miao J, Chen GG, et al. Increased expression of nucleophosmin/ B23 in hepatocellular carcinoma and correlation with clinicopathological parameters. Br J Cancer. 2007;96(3):477-484.

99. Ma H, Liang X, Chen Y, et al. Decreased expression of BATF2 is associated with a poor prognosis in hepatocellular carcinoma. Int J Cancer. 2011;128(4):771-777.

100. Gao Q, Wang XY, Qiu SJ, et al. Overexpression of PD-L1 significantly associates with tumor aggressiveness and postoperative recurrence in human hepatocellular carcinoma. Clin Cancer Res. 2009;15(3):971-979.
101. Zhai B, Yan HX, Liu SQ, Chen L, Wu MC, Wang HY. Reduced expression of E-cadherin/catenin complex in hepatocellular carcinomas. World J Gastroenterol. 2008;14(37):5665-5673.

102. Yu B, Yang X, Xu Y, et al. Elevated expression of DKK1 is associated with cytoplasmic/nuclear beta-catenin accumulation and poor prognosis in hepatocellular carcinomas. J Hepatol. 2009;50(5):948-957.

103. Tung EK, Mak CK, Fatima S, et al. Clinicopathological and prognostic significance of serum and tissue Dickkopf-1 levels in human hepatocellular carcinoma. Liver Int. 2011;31(10):1494-1504.

104. Xie H, Song J, du R, et al. Prognostic significance of osteopontin in hepatitis B virus-related hepatocellular carcinoma. Dig Liver Dis. 2007;39(2):167-172.

105. Korita PV, Wakai T, Shirai Y, et al. Overexpression of osteopontin independently correlates with vascular invasion and poor prognosis in patients with hepatocellular carcinoma. Hum Pathol. 2008;39(12):1777-1783.

106. Kornberg A, Küpper B, Thrum K, et al. Increased 18F-FDG uptake of hepatocellular carcinoma on positron emission tomography independently predicts tumor recurrence in liver transplant patients. Transplant Proc. 2009;41(6):2561-2563.

107. Cheung TT, Chan SC, Ho CL, et al. Can positron emission tomography with the dual tracers $[11 \mathrm{C}]$ acetate and $[18 \mathrm{~F}]$ fludeoxyglucose predict microvascular invasion in hepatocellular carcinoma? Liver Transpl. 2011;17(10):1218-1225

108. Yang SH, Suh KS, Lee HW, et al. The role of (18)F-FDG-PET imaging for the selection of liver transplantation candidates among hepatocellular carcinoma patients. Liver Transpl. 2006;12(11):1655-1660.

109. Lee JW, Paeng JC, Kang KW, et al. Prediction of tumor recurrence by 18F-FDG PET in liver transplantation for hepatocellular carcinoma. J Nucl Med. 2009;50(5):682-687.

110. Lee SD, Kim SH, Kim YK, et al. (18)F-FDG-PET/CT predicts early tumor recurrence in living donor liver transplantation for hepatocellular carcinoma. Transpl Int. 2013;26(1):50-60.

111. Kornberg A, Kupper B, Tannapfel A. Patients with non-[18 F] fludeoxyglucose-avid advanced hepatocellular carcinoma on clinical staging may achieve long-term recurrence-free survival after liver transplantation. Liver Transpl. 2012;8(11):53-61.

112. Hong G, Suh KS, Suh SW, et al. Alpha-fetoprotein and (18)F-FDG positron emission tomography predict tumor recurrence better than Milan criteria in living donor liver transplantation. J Hepatol. 2016;64(4):852-859.

113. Nel I, David P, Gerken GG, Schlaak JF, Hoffmann AC. Role of circulating tumor cells and cancer stem cells in hepatocellular carcinoma. Hepatol Int. 2014;8(3):321-329.

114. Ng CKY, di Costanzo GG, Terracciano LM, Piscuoglio S. Circulating cell-free DNA in hepatocellular carcinoma: current insights and outlook. Front Med (Lausanne). 2018;5:78.

115. Huang A, Zhang X, Zhou SL, et al. Plasma circulating cell-free DNA integrity as a promising biomarker for diagnosis and surveillance in patients with hepatocellular carcinoma. J Cancer. 2016;7(13):1798-1803.

116. Yin CQ, Yuan CH, Qu Z, Guan Q, Chen H, Wang FB. Liquid biopsy of hepatocellular carcinoma: circulating tumor-derived biomarkers. Dis Markers. 2016;2016:1427849-11.

117. Okajima W, Komatsu S, Ichikawa D, et al. Liquid biopsy in patients with hepatocellular carcinoma: circulating tumor cells and cell-free nucleic acids. World J Gastroenterol. 2017;23(31):5650-5668.

118. Zhou J, Huang A, Yang XR. Liquid biopsy and its potential for management of hepatocellular carcinoma. J Gastrointest Cancer. 2016;47(2):157-167.

119. Rodríguez-Perálvarez M, Tsochatzis E, Naveas MC, et al. Reduced exposure to calcineurin inhibitors early after liver transplantation prevents recurrence of hepatocellular carcinoma. J Hepatol. 2013;59(6):1193-1199.

120. Zhang Y, Li J, Cao L, Xu W, Yin Z. Circulating tumor cells in hepatocellular carcinoma: detection techniques, clinical implications, and future perspectives. Semin Oncol. 2012;39(4):449-460. 
121. Paterlini-Bréchot P, Vona G, Bréchot C. Circulating tumorous cells in patients with hepatocellular carcinoma. Clinical impact and future directions. Semin Cancer Biol. 2000;10(3):241-249.

122. Guo W, Sun YF, Shen MN, et al. Circulating tumor cells with stem-like phenotypes for diagnosis, prognosis, and therapeutic response evaluation in hepatocellular carcinoma. Clin Cancer Res. 2018;24(9):2203-2213.

123. Sánchez-Lorencio MI, Ramirez P, Saenz L, et al. Comparison of two types of liquid biopsies in patients with hepatocellular carcinoma awaiting orthotopic liver transplantation. Transplant Proc. 2015;47(9):2639-2642.

124. Yamashita T, Forgues M, Wang W, et al. EpCAM and alpha-fetoprotein expression defines novel prognostic subtypes of hepatocellular carcinoma. Cancer Res. 2008;68(5):1451-1461.

125. Nel I, Baba HA, Ertle J, et al. Individual profiling of circulating tumor cell composition and therapeutic outcome in patients with hepatocellular carcinoma. Transl Oncol. 2013;6(4):420-428.

126. Vona G, Estepa L, Béroud C, et al. Impact of cytomorphological detection of circulating tumor cells in patients with liver cancer. Hepatology. 2004;39(3):792-797.

127. $\mathrm{Xu} \mathrm{W}, \mathrm{Cao} \mathrm{L}, \mathrm{Chen} \mathrm{L}$, et al. Isolation of circulating tumor cells in patients with hepatocellular carcinoma using a novel cell separation strategy. Clin Cancer Res. 2011;17(11):3783-3793.

128. Schulze K, Gasch C, Staufer K, et al. Presence of EpCAM-positive circulating tumor cells as biomarker for systemic disease strongly correlates to survival in patients with hepatocellular carcinoma. Int $J$ Cancer. 2013;133(9):2165-2171.

129. Sun YF, XuY, Yang XR, et al. Circulating stem cell-like epithelial cell adhesion molecule-positive tumor cells indicate poor prognosis of hepatocellular carcinoma after curative resection. Hepatology. 2013;57(4):1458-1468.

130. Kelley RK, Magbanua MJ, Butler TM, et al. Circulating tumor cells in hepatocellular carcinoma: a pilot study of detection, enumeration, and nextgeneration sequencing in cases and controls. BMC Cancer. 2015;15:206.

131. Ramirez P, Sáenz L, Cascales-Campos PA, et al. Oncological evaluation by positron-emission tomography, circulating tumor cells and alpha fetoprotein in patients with hepatocellular carcinoma on the waiting list for liver transplantation. Transplant Proc. 2016;48(9):2962-2965.

132. von Felden J, Schulze K, Krech T, et al. Circulating tumor cells as liquid biomarker for high $\mathrm{HCC}$ recurrence risk after curative liver resection. Oncotarget. 2017;8(52):89978-89987.

133. Guo W, Yang XR, Sun YF, et al. Clinical significance of EpCAM mRNA-positive circulating tumor cells in hepatocellular carcinoma by an optimized negative enrichment and qRT-PCR-based platform. Clin Cancer Res. 2014;20(18):4794-4805.

134. Fan JL, Yang YF, Yuan CH, Chen H, Wang FB. Circulating tumor cells for predicting the prognostic of patients with hepatocellular carcinoma: a meta analysis. Cell Physiol Biochem. 2015;37(2):629-640.
135. Sun C, Liao W, Deng Z, et al. The diagnostic value of assays for circulating tumor cells in hepatocellular carcinoma: a meta-analysis. Medicine. 2017;96(29):e7513.

136. Xue F, Shi S, Zhang Z, et al. Application of a novel liquid biopsy in patients with hepatocellular carcinoma undergoing liver transplantation. Oncol Lett. 2018;15(4):5481-5488.

137. Wang S, Zheng Y, Liu J, Huo F, Zhou J. Analysis of circulating tumor cells in patients with hepatocellular carcinoma recurrence following liver transplantation. J Investig Med. 2018;66(5):1.6-6.

138. Huang Z, Hua D, Hu Y, et al. Quantitation of plasma circulating DNA using quantitative PCR for the detection of hepatocellular carcinoma. Pathol Oncol Res. 2012;18(2):271-276.

139. Ono A, Fujimoto A, Yamamoto Y, et al. Circulating tumor DNA analysis for liver cancers and Its usefulness as a liquid biopsy. Cell Mol Gastroenterol Hepatol. 2015;1(5):516-534.

140. Liao W, Yang $\mathrm{H}, \mathrm{Xu} \mathrm{H}$, et al. Noninvasive detection of tumorassociated mutations from circulating cell-free DNA in hepatocellular carcinoma patients by targeted deep sequencing. Oncotarget. 2016;7(26):40481-40490.

141. Chan KC, Lai PB, Mok TS, et al. Quantitative analysis of circulating methylated DNA as a biomarker for hepatocellular carcinoma. Clin Chem. 2008;54(9):1528-1536.

142. Divella R, Lacalamita R, Tommasi S, et al. PAI-1, t-PA and circulating hTERT DNA as related to virus infection in liver carcinogenesis. Anticancer Res. 2008;28(1A):223-228.

143. Ren N, Ye QH, Qin LX, Zhang BH, Liu YK, Tang ZY. Circulating DNA level is negatively associated with the long-term survival of hepatocellular carcinoma patients. World $J$ Gastroenterol. 2006;12(24):3911-3914.

144. Tokuhisa Y, Iizuka N, Sakaida I, et al. Circulating cell-free DNA as a predictive marker for distant metastasis of hepatitis $\mathrm{C}$ virus-related hepatocellular carcinoma. Br J Cancer. 2007;97(10):1399-1403.

145. Piciocchi M, Cardin R, Vitale A, et al. Circulating free DNA in the progression of liver damage to hepatocellular carcinoma. Hepatol Int. 2013;7(4):1050-1057.

146. Ikeda S, Tsigelny IF, Skjevik ÅA, et al. Next-generation sequencing of circulating tumor DNA reveals frequent alterations in advanced hepatocellular carcinoma. Oncologist. 2018;23(5):586-593.

147. Zucman-Rossi J. Molecular classification of hepatocellular carcinoma. Dig Liver Dis. 2010;42(Suppl 3):S235-S241.

148. Patel A, Sun W. Molecular targeted therapy in hepatocellular carcinoma: from biology to clinical practice and future. Curr Treat Options Oncol. 2014;15(3):380-394.

149. Huang A, Zhao X, Yang XR, et al. Circumventing intratumoral heterogeneity to identify potential therapeutic targets in hepatocellular carcinoma. J Hepatol. 2017;67(2):293-301.
Journal of Hepatocellular Carcinoma

\section{Publish your work in this journal}

The Journal of Hepatocellular Carcinoma is an international, peerreviewed, open access journal that offers a platform for the dissemination and study of clinical, translational and basic research findings in this rapidly developing field. Development in areas including, but not limited to, epidemiology, vaccination, hepatitis therapy, pathology and
Dovepress

molecular tumor classification and prognostication are all considered for publication. The manuscript management system is completely online and includes a very quick and fair peer-review system, which is all easy to use. Visit http://www.dovepress.com/testimonials.php to read real quotes from published authors. 